\title{
Determinants of Smallholder Farmers' Participation in Improved Sheep Production: The Case of Doyogena District, Kembata Tembaro Zone, Southern Ethiopia
}

\author{
Teketel Mathewos, ${ }^{1}$ Daniel Temesgen, ${ }^{2}$ Dereje Hamza, ${ }^{2}$ and Haben Fesseha $\mathbb{D}^{3}$ \\ ${ }^{1}$ College of Agriculture, Wolaita Sodo University, P.O. Box 138, Wolaita Sodo, Ethiopia \\ ${ }^{2}$ College of Agriculture, Jimma University, Jimma, Ethiopia \\ ${ }^{3}$ School of Veterinary Medicine, Wolaita Sodo University, P.O. Box 138, Wolaita Sodo, Ethiopia
}

Correspondence should be addressed to Haben Fesseha; haben.senbetu@wsu.edu.et

Received 9 January 2021; Accepted 30 August 2021; Published 14 September 2021

Academic Editor: Yunchao Tang

Copyright (c) 2021 Teketel Mathewos et al. This is an open access article distributed under the Creative Commons Attribution License, which permits unrestricted use, distribution, and reproduction in any medium, provided the original work is properly cited.

\begin{abstract}
Background. Improved sheep production practices are becoming relevant, but smallholder farmers' involvement in improved sheep production was below expectations and detailed studies were restricted on the determinants of the participation of smallholder farmers in improved sheep production. This research was conducted to examine the determinants of the involvement of smallholder farmers in enhanced sheep production in the study area. Methods. Multi-stages sampling techniques were used for this study. Firstly, improved sheep production had a big effect on the incomes of households of participants and nonparticipants. Finally, three kebeles were chosen by basic random sampling, and the third was picked for systematic sampling by 144 survey respondents. Quantitative and qualitative data were gathered from primary and secondary sources. Data collection techniques were undertaken by surveys, focus group discussions, and key informants. Quantitative data were used to evaluate descriptive statistics, such as average, frequency, standard deviation, scope, and inferential $t$-test and chi-square statistics, and a logit model. Qualitative data obtained from focus group discussion and key informants were analyzed by narrative and used for survey data triangulation. Results. Out of the 144 samples, 51 were participants and 93 were nonparticipants. Participation determinants found in this research field were household labor, age, communication frequency with developers, membership in cooperatives, land ownership, participation in credit, and off-farm income. Improved sheep production had a major effect on the incomes of households of participants and nonparticipants. Multiple determinants typically affect the role of smallholder farmers in raising sheep production. Conclusion. Future initiatives under a successful policy should aim at accelerating agricultural and rural growth by efficiently leveraging enhanced sheep capacity in particular in the study region and Ethiopia in general.
\end{abstract}

\section{Introduction}

Ethiopia, which accounts for $50 \%$ of the total agricultural share of the gross domestic product (GDP), $85 \%$ of exports, $80 \%$ of the total jobs as well as domestic raw material for the smallscale industry of this region, has been thought to have the largest livestock population in Africa [1]. It is used to manage food, crop input, soil fertility, industry raw materials, cash income, saving, fuel, social functions, and employment [2].

The pressure of populations decreases farm size and at the same time, because of its lower competition for arable land, the position of large ruminants is decreased [3]. Sheep need small investments, need shorter production cycles, have higher rates of growth and environmental adaptability in contrast to large ruminants, and thus are exceptional for smallholder farms [4]. Sheep are mainly used for cash production where precipitation is unpredictable, and where poor people are interested in owning and sustaining their sheep for immediate generation of income [5]. Sheep usage as a source of income for farm inputs reduces risks related to crop production in mixed farming and creates employment, saving, and money [6]. 
According to Lakew et al. [5], sheep in Ethiopia play a multifunctional role in the cash, meat, skin, manure, and long hairy fleece with regard to smallholder farmers. Increased production of ovine animals is thus necessary to fulfill the demands of the rising human population. On the other hand, improving the productivity of sheep and export earnings will improve the income of the household [7]. The study done by Gowane et al. [8] confirmed that sheep are relatively resilient to higher temperatures than cattle and rising temperatures will lead to a growing increase of sheep due to climate change.

The production of sheep provides protection in times of crop failure, which is projected to be "near-cash" equity [9]. Similarly, Ahmed [10] insists that sheep enterprise in Ethiopia is the source of cash income and provides social security in the bad crop years. Moreover, in Ethiopia, sheep provide almost $15 \%$ of fresh skins and hide production and $72 \%$ of semiprocessed skins and hide export trade [11]. The annual mutton production in the country is estimated at 78,000 Metric Ton (MT) [6]. Sheep are important in terms of food security and poverty, particularly for the poor and the women who are often vulnerable in society and who contribute to the generation of cash income [12].

According to Central Statistics Authority (CSA) [13], a survey in Ethiopia indicated that the potential of sheep is very high; 30.70 million sheep are estimated to be found in the country, out of which about 5,087,007(17\%) are found in SNNPR, and from 5,087,007 around 109, 732 (2.2\%) are found in the Kembata Tembaro zone, and from 109,732 about $32920(30 \%)$ are found in the Doyogena district. This zone is noted for mixed farming activity that has a high cultivation and livestock potential. The biodiversity of the region is mainly high ground. Highlands in Ethiopia are considered to be potential for sheep production [14].

Improved livestock production became significant, but the involvement of small-scale farmers in the production of sheep was not as anticipated and the study did not show why participation was reduced [15]. Ethiopian national sheep production program aims to increase sheep per capita rather than maintain an incredibly large number of unproductive ovine animals that lead to land loss, food shortages, and consumption of large resources [16]. Despite the well-adapted and large sheep population, current productivity and involvement in improved sheep production for smallholders is poor and for different reasons, the country cannot achieve the anticipated benefit from ovine production [17].

Several small-scale farmers have been focusing on developing sheep production programs in southern Ethiopia. However, smallholder farmers are still in doubt and for various factors decided to control increased livestock production [1]. Studies in Mareko district, Gurage zone show that farmers' decision to participate in improved sheep production was determined by the combined effects of several factors such as lack of access to improved breeds, age, socioeconomic (membership of cooperative, land size, farm income, labor) and institutional factors like access to animals' health services, credit utilization distance from kebele center, and extension contact [18].
A few studies have been performed in the field of research on sheep production, but not explicitly, to explain the determinants of the involvement of smallholder farmers in improved sheep production in the region. For example, the study conducted by Getachew et al. [19] and Gizaw et al. [20] was not focused on identifying the determinants of farmers' participation in improved sheep production. While agricultural development workers and researchers are making big and ongoing efforts, involvement in improved production of ovine animals has not reached the desired level. The research will also help to gain accurate knowledge that can be useful to promote and enhance the production and productivity of improved sheep, as well as to recognize and interfere with negative participatory determinants of the smallholder farmers. Thus, this study was designed to analyze the determinants of smallholder farmers' participation in improved sheep production in Doyogena district, Kembata Tembaro Zone, Southern Ethiopia.

\section{Methodology}

2.1. Study Area. Doyogena is one of the districts in the Kembata Tembaro zone, Southern Nations, Nationalities, and People's Region which is a high land area. The area is about $258 \mathrm{~km}$ from Addis Ababa in the southern direction and $171 \mathrm{~km}$ southwest of Hawassa. The district comprises mostly high land agro-ecological zone and its altitude ranges from 1900 to 2800 m.a.s.l. Annual rainfall is $1200-1800 \mathrm{~mm}$ and the mean temperature varies from 10 to $18^{\circ} \mathrm{C}$ [21]. The total population of the district is 116,048 , comprising 56,863 males and 59,185 females. The district has a total of 32,920 sheep, out of which 10,534 were improved. The majority of the population is dependent on mixed agriculture, with income of $60 \%$ of the households $(\mathrm{HH})$ from crop production and $40 \%$ of households from livestock production. Among livestock production, $19 \%$ is from sheep and $21 \%$ from other species (Figure 1) [22].

2.2. Study Design. A cross-sectional design was used in this study. Quantitative data were collected and appropriate analytic techniques were employed to meet the objectives of the study. Effective measurement methods to fulfill the aims of this study were employed and quantitative data were obtained. Using an interview schedule, quantitative data were gathered to assess the significant data, and generalizations were drawn from the result.

\subsection{Sampling Method and Sample Size Determination.}

For this study, the multi-stage sampling technique was used. Firstly, the Doyogena district was selected purposively, due to the existence of improved sheep production experiences and its accessibility. Secondly, three kebeles, namely, Serara Bokata, Ancha Sedicho, and Hawora Arara were selected by simple random sampling technique due to their similar production potential. Thirdly, 144 sample households were selected by systematic random sampling methods from all three kebeles. 


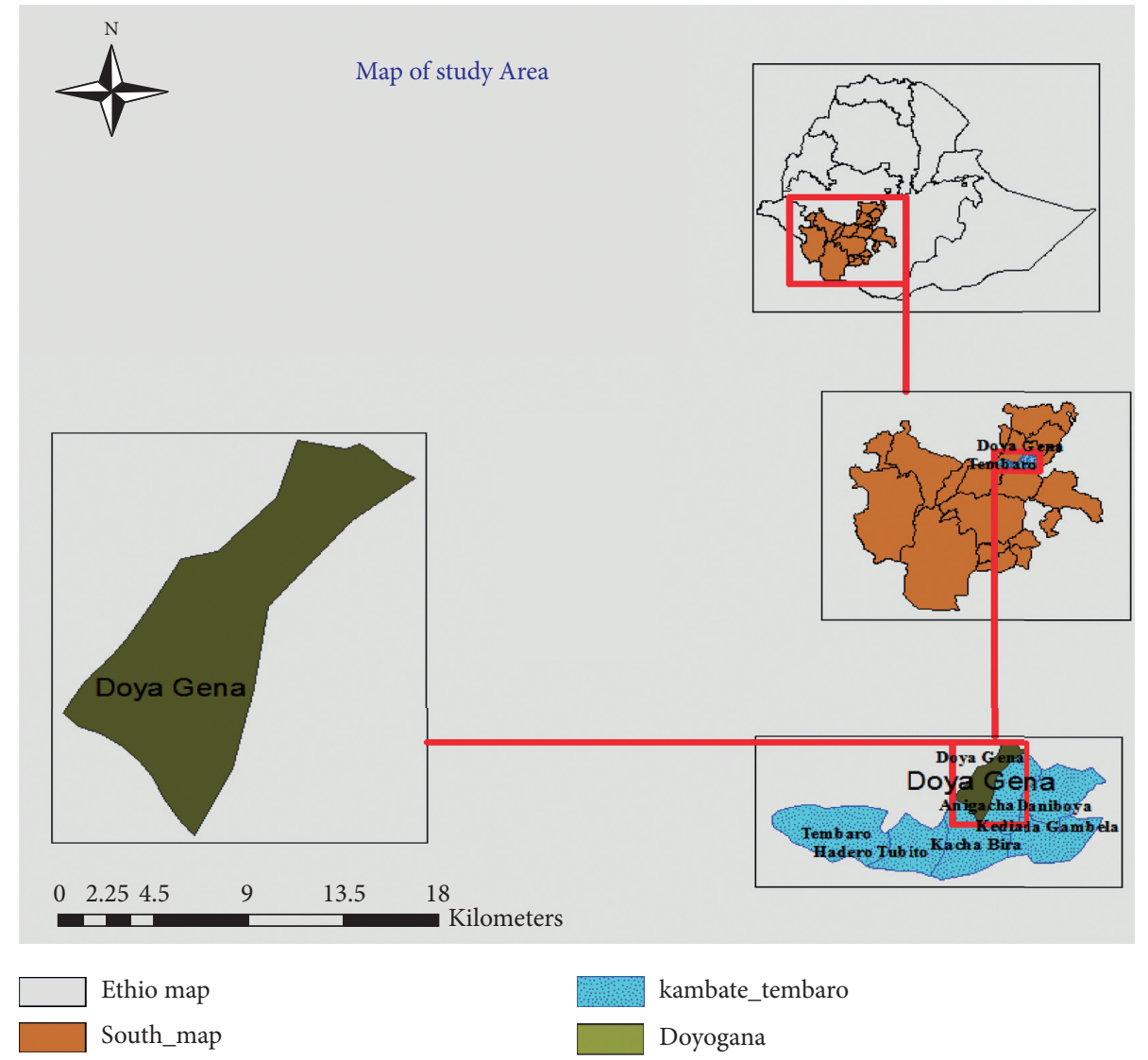

Figure 1: Map of the study area.

The sample size determination was computed by using Yamane [23] sampling formula at 95\% confidence interval, with the level of precision of $8 \%$

$$
\begin{aligned}
& n=\frac{N}{1+N(e)^{2}}, \\
& n=\frac{1900}{1+1900(.08)^{2}}=144,
\end{aligned}
$$

where $n$ is the sample size, $N$ is the population size (total household heads size), and $e$ is the level of precision.

In general, the sample size, total number of sheep producers' household heads from the kebeles, and the proportion of sample size are summarized in Table 1.

2.4. Methods of Data Collection. Both quantitative and qualitative types of data were gathered through different data collection methods from primary and secondary sources. The data from both primary and secondary sources were collected and used to generate valuable information. Primary data sources were 144 sample respondents, key informants, and focus group discussions. Secondary data sources were Areka research center (branch at Doyogena), district's livestock and fishery, cooperative development, agriculture and natural resources, finance and economy and trade and industry offices, and relevant published and unpublished reports.
(1) Individual Interview. Totally, 144 sample respondents were selected and considered for an interview. Three enumerators who have a college diploma and experience in agricultural activities were recruited and trained to implement both qualitative and quantitative data collection using an interview schedule. Before data collection, the interview schedule was translated into the local language (Kembatigna) and pretested on nine farmers who were not included in the final sample households. Hence, appropriate modifications and corrections were made to the questionnaire, and data were collected under the continuous supervision of the researcher.

(2) Key Informants' Interview. For this study, in addition to individual interviews, data from key informants (KI) were also collected from development agents (coordinators), managers of respective kebeles, district's livestock and fishery, agriculture, and natural resources, cooperative development, trade, and the industry as well as administration offices expertise focal persons (total of eleven key informants). These participants were selected purposively to obtain relevant data.

(3) Focus Group Discussion. Focus group discussions were held with three groups, one in each kebele (including twelve members in each group). The composition of groups was farmers such as development group leaders, model, and nonmodel farmers as well as respective kebeles' leaders who were selected purposively for seeking appropriate information. It was also aimed to increase the reliability and 
trustworthiness of the information. The group members were familiarized with the discussion points and encouraged to forward their opinion without any reservation. The idea of dominance was tried to control as much as possible to avoid sampling bias. Both key informants and focus group discussions were mainly used to generate qualitative data that supported the findings of the survey based on predetermined checklists.

2.5. Data Management and Data Analysis. After compiling and screening, the interview data of 144 respondents were analyzed. Descriptive and econometric analyses were used to analyze the data collected from respondents. Both descriptive and econometric methods were employed to analyze the relationship between dependent and explanatory variables by using the Statistical Package for Social Sciences (SPSS, version 20). Inferential statistics such as Chi-square $\left(X^{2}\right)$ and $t$-tests were used. Also, qualitative analysis was used to compare the socioeconomic, demographic, and situation of respondents as well as triangulating survey data.

2.5.1. Econometric Analysis. The purpose of this study was to analyze the determinants of participation of smallholder farmers in improved sheep production. The dependent variable, in this case, is a dichotomous variable, which takes a value of 1 if the household participates, and otherwise 0 . Demographic and socioeconomic characteristics, as well as institutional factors that were assumed to be correlated with the participation of improved sheep production, were entered along with these classifications.

Models, which include a "yes" or "no" type-dependent variable, are called dichotomous or dummy variable regression models. Such models approximate the mathematical relationship between explanatory variables and the dependent variable that is always assigned qualitative response variables [24]. The four most commonly used approaches to estimate dummy-dependent variable regression models are (a) the linear probability model (LPM), (b) the logit, (c) the probit, and (d) the Tobit model. They are applicable to a wide variety of fields [24].

The major point that distinguishes these functions from the linear regression model is that the outcome variable in these functions is binary or dichotomous. Besides, the difference between logistic and linear regression is reflected both in the choice of a parametric model and in the assumptions. Once this difference is accounted for, the methods employed in analysis using logistic regression follow the same general principles used in linear regression [25].

The probability model, which expresses the dichotomous dependent variable $\left(Y_{i}\right)$ as a linear function of the explanatory variables $\left(X_{i}\right)$, is called the linear probability model (LPM). Due to econometric shortcomings like nonnormality of the disturbances (Ui), heteroscedastic variances of the disturbances, nonfulfillment of $0<\mathrm{E}(\mathrm{Yi} / \mathrm{Xi})<1$, and lower value of R2, linear probability model (LPM), as a measure of goodness of fit, failed to test the statistical significance of estimated coefficients. In the case of logit and probit, the estimated probabilities lay between logical limit 0 and 1 , and they are the most frequently used models when the dependent variable happens to be dichotomous, as well as the choice between these two models revolves around practical concerns such as the availability and flexibility of computer program, personal preference, experience, and other facilities. In fact, it represents a close approximation to the cumulative normal distribution [24].

Crowder [26] pointed out that a logistic distribution has got advantages over others in the analyses of the dichotomous outcome variables. There are two primary reasons for choosing the logistic distribution. These are: (a) from a mathematical point of view, it is an extremely flexible and easily used function and (b) it tends itself to a logically meaningful interpretation also states that the logit model is simpler in estimation than the probit model. After reviewing the strengths, drawbacks, and assumptions of different models, the binary logistic regression model was employed to address the core objective of the study, i.e., analyzing determinants of participation of smallholder farmers in improved sheep production

$$
\begin{aligned}
& P(x)=E\left(Y=\frac{f}{x}\right) \\
& P(x)=E\left(y=\frac{1}{x}\right)=\frac{1}{1+e-(B 0+B i X i)} .
\end{aligned}
$$

For ease of exposition, we write equation (2) as

$$
P(x)=\frac{1}{1+e^{-z i}},
$$

where $P(x)=$ is a probability of being participant and ranges from 0 to $1 ; Z_{\mathrm{i}}=$ is a function of n-explanatory variables $(x)$ which is also expressed as

$$
\begin{aligned}
Z_{i}= & B_{0}+B_{1} X_{1}+B_{2} X_{2}+\cdots+B_{n} X_{n}, \\
\text { PART }= & \beta_{0}+\beta_{1} \mathrm{AG}+\beta_{2} \mathrm{SEX}+\beta_{3} \mathrm{EDU}+\beta_{4} \mathrm{LOBOUR}+\beta_{5} \mathrm{LAND} \mathrm{SZ}+\beta_{6} \mathrm{FI} \\
& +\beta_{7} \mathrm{OFI}+\beta_{8} \mathrm{CU}+\beta_{9} \mathrm{MSC}+\beta_{10} \mathrm{DFKC}+\beta_{11} \mathrm{FDC}+\beta_{12} \mathrm{AHS}+\beta_{13} \mathrm{DFNMC},
\end{aligned}
$$

where, $X_{1}=$ Age of the household head, $X_{2}=$ Sex of household head, $X_{3}=$ Education level of the household head, $X_{4}=$ Household labor size in ME, $X_{5}$ Land size owned by
HH, $X_{6}=$ Farm income, $X_{7}=$ Off-farm income, $X_{8}=$ Credit utilization, $X_{9}=$ Membership of cooperatives, $X_{10}=$ Distance from kebele center, $X_{11}=$ Frequency of contact with 
TABLE 1: Sample size determination from selected kebeles

\begin{tabular}{lcccccc}
\hline \multirow{2}{*}{ Kebeles } & \multicolumn{3}{c}{$\begin{array}{c}\text { Population }(\mathrm{HH} \\
\text { heads) }\end{array}$} & \multicolumn{3}{c}{ Sample size } \\
& Male & Female & Total & Male & Female & Total \\
\hline Serera-Bokata & 342 & 242 & 584 & 32 & 13 & 45 \\
Ancha-Sedicho & 396 & 288 & 684 & 36 & 16 & 52 \\
Hawora-Arara & 353 & 279 & 632 & 32 & 15 & 47 \\
Total & $\mathbf{1 0 9 1}$ & $\mathbf{8 0 9}$ & $\mathbf{1 9 0 0}$ & $\mathbf{1 0 0}$ & $\mathbf{4 4}$ & $\mathbf{1 4 4}$ \\
\hline
\end{tabular}

Source: computed from own survey data, 2018.

development agents, $X_{12}=$ Access to animals' health serves, $X_{13}=$ Distance from near market center, $B_{0}=$ intercept, $B_{1}$, $B_{2} \ldots B_{n}=$ Slopes of the equation in the model.

The probability that a given household participant is expressed by equation (3) while the probability of not participating is

$$
1-P(x)=\frac{1}{1+e^{z i}} .
$$

Therefore, we can write

$$
\frac{P(x)}{1-P(x)}=\frac{1+e^{z i}}{1+e^{-z i}}=e^{z i} .
$$

Now $P(x) /(1 P(x))$ is simply the odds ratio in favor of participation. It is the ratio of the probability that a household participated to the probability that did not participate. Finally, taking the natural log of equation (6) we obtain

$$
\begin{aligned}
L_{i} & =\frac{\ln [P(x)]}{1-P(x)}=Z_{i}, \\
Z_{i} & =B_{0}+B_{1} X_{1}+B_{2} X_{2}+\cdots+B_{n} X_{n} .
\end{aligned}
$$

If the disturbance term, $\left(U_{i}\right)$ is introduced, the logit model becomes

$$
Z_{i}=B_{0}+B_{1} X_{1}+B_{2} X_{2}+\cdots+B_{n} X_{n}+U_{i},
$$

where $L_{i}=\log$ of the odds ratio, which is not only linear in $X_{i}$ but also linear in the parameters, $X_{i}=$ Vector of relevant explanatory variables.

Changing an independent variable, in this case, was expected to alter the probability that a given individual becomes a participant, and this helped to predict the probability of participating.

2.5.2. Estimation Procedure. Given that the model selected for analysis was the binary logit model, the dependent variable was assigned by a value of 1 or 0 , representing participant or nonparticipant, respectively. Estimating the values of $B_{0}$ and $B_{i}$ 's, a set of data were fitted into equation (8). Since the method of Ordinary Least Square (OLS) does not make any assumption about the probabilistic nature of the disturbance term $\left(U_{i}\right)$, the parameters of the model are estimated using the maximum likelihood (ML) method [24].

Before employing the logit model, the existence of multicollinearity among the continuous variables was checked and the association among discrete variables was also verified by checking covariance. The existence of multicollinearity seriously affects the parameter estimates. In short, the coefficients of the interaction of the variables indicate whether one of the two associated variables should be eliminated from the model analysis [27].

Accordingly, Variance Inflation Factors (VIF) technique was employed to distinguish the problem of multicollinearity for continuous explanatory variables [24]. Each selected continuous variable was regressed on the other continuous explanatory variables and an evaluation was made on the coefficient of determination $\left(R_{j}^{2}\right)$. If an approximately linear relationship exists among the explanatory variables, then this results in a "large" value for $R^{2}{ }_{j}$ in at least one of the test regressions. A popular measure of multicollinearity is VIF defined as

$$
\operatorname{VIF}\left(X_{j}\right)=\frac{1}{1-R_{j}^{2}} .
$$

A rise in the value of $R_{j}^{2}$, which is an increase in the degree of collinearity, does indeed lead to an increase in the variances and standard errors. A VIF value greater than or equal to 10 is used as a signal for the strong collinearity. In the same way, it is necessary to test whether there is or not the interaction between discrete variables that can lead to the problem of association among each other using coefficients of contingency (CC). If the value of CC is greater than or equal to 0.75 it is used as a signal for the existence of strong association among the discrete variables [24].

$$
\mathrm{CC}=\sqrt{\frac{X^{2}}{n+X^{2}}}
$$

where CC is the coefficient of contingence, $x^{2}$ is the chisquare test, and $n$ is the total sample size.

\subsection{Definition of Variables}

2.6.1. Dependent Variable of the Model. The dependent variable for this study was smallholder farmers' participation in improved sheep production. Participation "(Participating in Improved Sheep Production, "PISP")" which was the dependent variable for the binary logit analysis as a dichotomous variable and represented by 1 for participant and 0 for nonparticipant household heads.

2.6.2. Independent Variables of the Model. After the logical procedure was clearly delineated, the potential explanatory variables were identified that determined the participation of smallholder farmers in improved sheep production. The independent variables of the study are variables that are expected to influence farmers' participation in improved sheep production and can be of many types. Here, an explanation of the thirteen potential hypothesized explanatory variables was presented.

Consequently, a review of literature, past research findings, and expert opinions were used to identify the potential determinants of the participation of farmers in 
improved sheep production in the study area. Thus, taking participation as the dependent variable, the following explanatory variables were identified and their influence on the participation of smallholder farmers examined.

(1) Age of the Rural Farm Household Head (AG). It is a continuous variable, defined as the farm household head's age and measured as the number of years from the dates of birth to the day of the survey interview. When farmers' age increases, their maturity also increases and they will be eager to apply new technology. According to Assan [28], those household heads of a matured age due to a good farm experience have a much better association with more productivity. Hence, in this study, it was hypothesized that when the household head's age increases, it affects participation in improved sheep production positively and significantly.

(2) Sex of the Household Head (SEX). this is a dummy variable that assumes a value of " 1 " if the head of the household is male, and "0" otherwise. Sex is a biological difference between being male or female respondents. With this background, male-headed households have a better probability of mobility, participate in different meetings, and have more exposure to information about better production participation. According to Urgessa [29], women-headed households are less likely to control economic resources and the nature of their economic activity. Then, it was hypothesized that male-headed households have more chance to participate in improved sheep production and positively and significantly influence it.

(3) Education Level of Household Head (EDU). It is a continuous variable and is measured by years of schooling. When the education levels of farmers increase, they have a better ability to identify the problem of their farm income as well as calculate its costs and benefits. According to Mathebula [30], a high level of education was expected to facilitate more exposure to the external environment and accumulation of knowledge on farming practices. Therefore, in this study, it was hypothesized that advanced school levels affect participation in improved sheep production positively and significantly.

(4) Household (HH) Labor in Me. It is a continuous variable and is measured by several members under the control of one HH head in man equivalent (ME) ratio. Sheep management involves time-consuming labor and availability of labor can ease the management of sheep in a household. According to Haile et al. [31], in farming households, for improved sheep rearing and routine management practices, the availability of productive labor is mandatory. Hence, in this study, availability of labor was hypothesized, which affects the participation of smallholder farmers in improved sheep production positively and significantly.

(5) Size of Land in Hectares (LAND SZ). Land is a continuous variable measured in the number of hectares by the household. Land is one of the key productive resources for smallholder farmers to generate their livelihood. Owning a large area of land can be a means of accumulating wealth and a source of animal feed. Households who have better landholding have a better capacity to participate in improved sheep production. According to Mueller et al. [32], a large size of land implies more possibility of having a large flock size and availability of feeds. In this study, it was hypothesized that the size of landholding by the household has a positive and significant influence on the participation of improved sheep production.

(6) Farm Income (FI). It is a continuous variable measured in the amount of money the household earns annually from the sale of agricultural products (both crop and livestock) in ET B. The increase in the productivity of agriculture enables to get huge money and enhancing improved breed and other production input purchasing power. According to Rasch et al. [33], rural households with better farm income have a better possibility of participating in improved sheep production. In this study, it was hypothesized that better farm income influences smallholder farmers' participation in improved sheep production positively and significantly.

(7) Off-Farm Income (OFI). It is a continuous variable measured by the amount of money the household earns annually from the sale of the family business, remittance, a day's labor in other's farm, or nonfarm activities, and any other income sources in ET Br. When households get adequate off-farm income, they can have the capacity to run improved sheep production. According to Babatunde et al. [34], off-farm income is a determining explanatory variable that can positively affect the probability of participation in improved sheep production. In this study, it was hypothesized that getting off-farm income influences smallholder farmers' participation positively and significantly.

(8) Credit Participation (CP). It is a dummy variable that takes the value of 1 if the household utilized credit, and 0 otherwise. Credit is an important instrument to solve the liquidity problem that farm households are facing. Households who participated in credit could purchase agricultural inputs including livestock. According to Kebebe [35], credit participation can ensure that households purchase improved breed and other production inputs. In this study, the credit part was hypothesized that credit participation influences smallholder farmers' participation in improved sheep production positively and significantly.

(9) Membership of Cooperatives (MSC). This was coded as a dummy variable, which took the value of 1 if the farmer was a member of cooperatives, and 0 otherwise. Cooperative societies are one of the important institutions in rural and agricultural development. Cooperatives serve as an important source of rural credit and producers who are a member of cooperatives are likely to get inputs and production information and thus could participate and supply sheep to the market than nonmembers. According to Hennessy et al. [36], membership in farmers' cooperatives significantly raised the probability of technology adoption. Therefore, in this study, being a member of a cooperative was hypothesized that 
membership of cooperatives has a positive and significant relationship with participation in improved sheep production.

(10) Distance from the Kebele Center (DFKC). It is a continuous variable measured by several kilometers from the center of the kebele to their home. Distance from the kebele center is the number of kilometers farmers walk to reach the kebele center. Farmers living closer to kebele centers are likely to get updated information and adopt improved sheep breeds than those who are living far. According to Deresse et al. [37], when farmers come from far, the probability of improving agricultural technology adoption decreases. It was hypothesized that distance affects participation in improved sheep production negatively and significantly.

(11) Frequency of Extension Contact (FDC). It is a continuous variable measured by the number frequency of contacts per year that the respondent makes with development agents. The frequency of extension contact is one type of sharing knowledge and experience with development agents. According to Elias et al. [38], farmers who make contact with development agents frequently have better access to information on technology and have a better possibility to translate their intentions into action. In this study, it was hypothesized that maximum frequency of extension contact with development agents has a positive and significant influence on smallholder farmers' participation in improved sheep production.

(12) Access to Animals' Health Service (AHSC). It is a dummy variable; it takes the value 1 if the respondent gets access, and " 0 " otherwise. Access to health services is a very critical variable that can affect the motivation of farmers to participate in improved sheep production. When sheep health care access is improved, productivity will increase as well as farmers will be encouraged to participate in improved sheep production. According to Robinson et al. [39], unless a farmer having access to health services, he/she cannot decide to participate in improved sheep production. So, in this study, it was hypothesized that improvement in access to animals' health services affects the decision to participate in improved sheep production positively and significantly.

(13) Distance to the Nearest Market Center (DTNMC). It is a continuous variable that can be measured by the number of kilometers it takes from their home to reach the nearest the market. The closer they are to the nearest market, the more likely they have updated market information and are enabled to participate in improved and intensive farming activities. Meanwhile, for the farmers who live far away from market places, the likelihood of adopting the technology will decrease $[40,41]$. So, in this study, it was hypothesized that distance from the nearest market to their home is expected to influence participation in improved sheep production negatively and significantly.

\section{Results and Discussion}

3.1. Demographic and Socioeconomic Characteristics of Sheep Producer Sample Households. In total, 144 sample households' heads were considered in this study. As shown in Table 2, out of the total sample respondents, 100 (69.4\%) and 44 (30.6\%) were male- and female-headed, respectively. The overall mean age of the sampled household head was 53 years with a standard deviation of 5.67; this implies that the majority of them were in the working age group, and the age difference among farmers was 5.67 years.

The other demographic characteristic was education level. The average education grade level was grade 4 with a standard deviation of 1.29 , which indicates that the major group of farmers had similar lower grades. The average land holding was 1.47 hectares with a standard deviation of 0.39 . This is less than the national average, which is 1.37 hectares, but it can vary from place to place [1].

As described in Table 3, the major crop in the study area was wheat, which covers $42.5 \%$ of the total cultivable land. Potato (14\%) is the second most produced crop in cultivable lands of the highland areas. The livestock production was also another farm practice that used the mixed approach and the most dominant livestock types were cattle and sheep.

As described in Table 4, the study area is known for land shortage, as most of (67.7\%) the land is cultivable land, $19.75 \%$ is forest land, and only $6.14 \%$ is grazing land that can be used for livestock production.

\subsection{Descriptive Statistics Analysis for Discrete Variables}

3.2.1. Household Heads' Sex. The result in Table 5 shows that 144 respondents were included in this study: 100 (69.4\%) and $44(30.6 \%)$ from male-headed and female-headed households, respectively. Out of 51 participants, $42(82.4 \%)$ were from male-headed households and 9 (17.6\%) were from female-headed HHs. But in the nonparticipant group, out of 93 nonparticipants, 58 (62.4\%) were from male-headed $\mathrm{HHs}$ and $35(37.6 \%)$ were from female-headed HHs. The participation of females in improved sheep production is still very least.

The study result showed that the biological differences between males and females influenced participation significantly at a $1 \%$ significance level $\left(X^{2}=6.201^{* * *} ; p \leq 0.01\right)$. Based on evidence obtained from focus group discussions, male dominance on resources was very high. Due to this, contacts with development agents to share new information and knowledge enabled males better than females. It is in line with the study of Musgrave [42], and production of sheep needs high production resources and power due to this most of the time males have been suitable to undertake heavy management activities than females.

3.2.2. Access to Animal Health Services. Accessibility of animal health services is one of the crucial factors for the production and productivity of sheep. The result of this study, as shown in Table 5, indicated that out of 51 participants, $36(70.6 \%)$ participants in improved sheep production had access to animal health services. Out of 51 
TABLE 2: Demographic and socioeconomic characteristics of sample sheep producers.

\begin{tabular}{lccc}
\hline Variable & & Frequency & Percentage \\
\hline \multirow{2}{*}{ Sex } & Male & 100 & 69.4 \\
& Female & 44 & 30.6 \\
\hline & & Mean & Standard deviation \\
Age in year (AGE cont) & & 53 & 5.6695 \\
Educational status (EDU) & & 4 & 1.2975 \\
Land size & & 0.935 & 0.356 \\
\hline
\end{tabular}

Source: computed from own survey data, 2018.

TABLE 3: The Livestock and crop types in the study area.

\begin{tabular}{|c|c|c|c|c|}
\hline Types of crops grown in the study districts & Land coverage $(\mathrm{Ha})$ & Land coverage in percent & Types of livestock & Number of livestock \\
\hline Wheat & 5200 & 42.5 & Total sheep & 32920 \\
\hline Barley & 1221 & 10 & Improved sheep & 10534 \\
\hline Teff & 1450 & 12 & Goat & 4501 \\
\hline Pulse crops & & & Pack animals & 10213 \\
\hline Faba bean & 1036 & 8 & Bee in hive & 3101 \\
\hline Haricot bean & 450 & 4 & & \\
\hline Field pea & 295 & 2 & & \\
\hline Potato & 1750 & 14 & & \\
\hline Enset & 714 & 6 & & \\
\hline Oil crops & 20 & 0.5 & & \\
\hline Others & 112.60 & 1 & & \\
\hline Total & $12,248.60$ & & & \\
\hline
\end{tabular}

Source: computed from own survey data, 2018.

TABLE 4: The land use of farmers in the study area.

\begin{tabular}{lcc}
\hline Types of land use & Coverage in hectare $(\mathrm{Ha})$ & Percentage $(\%)$ \\
\hline Cultivated land & $12,248.6$ & 67.7 \\
Grazing land & 1110 & 6.14 \\
Forest land & 3573 & 19.75 \\
Degraded land & 435 & 2.4 \\
Swampy land & 358.33 & 1.98 \\
Potentially cultivable land & 202.4 & 1.13 \\
Others & 164.01 & 0.9 \\
Total & $\mathbf{1 8 , 0 9 1 . 3 4}$ & \\
\hline
\end{tabular}

Source: computed from own survey data, 2018.

TABLE 5: Descriptive statistics' results of discrete explanatory variables.

\begin{tabular}{|c|c|c|c|c|c|c|c|}
\hline \multirow{2}{*}{ Variables } & & \multicolumn{2}{|c|}{ Participants } & \multicolumn{2}{|c|}{ Nonparticipants } & \multirow{2}{*}{$P$ value } & \multirow{2}{*}{ Chi-square } \\
\hline & & Freq. & $\%$ & Freq. & $\%$ & & \\
\hline \multirow{3}{*}{ Sex } & Male & 42 & 82.4 & 58 & 62.4 & 0.009 & $6.201^{* * *}$ \\
\hline & Female & 9 & 17.6 & 35 & 37.6 & & \\
\hline & Total & 51 & 100 & 93 & 100 & & \\
\hline \multirow{3}{*}{ Access to animals health services (AHS) } & Yes & 36 & 70.6 & 24 & 25.8 & 0.0001 & $27.176^{* * *}$ \\
\hline & No & 15 & 29.4 & 69 & 74.2 & & \\
\hline & Total & 51 & 100 & 93 & 100 & & \\
\hline \multirow{3}{*}{ Membership of cooperatives (MSC) } & Yes & 38 & 74.5 & 25 & 26.9 & 0.0001 & $30.361^{* * *}$ \\
\hline & No & 13 & 25.5 & 68 & 73.1 & & \\
\hline & Total & 51 & 100 & 95 & 100 & & \\
\hline \multirow{3}{*}{ Credit utilization (CU) } & Yes & 40 & 78.4 & 30 & 32.3 & 0.0001 & $28.110^{* * *}$ \\
\hline & No & 11 & 21.6 & 63 & 67.7 & & \\
\hline & Total & 51 & 100 & 93 & 100 & & \\
\hline
\end{tabular}

(Source: computed from own survey data, 2018); Freq. = frequency; \% = percentage; $p=$ probability; ${ }^{* * *},{ }^{* *}(1 \%$ and $5 \%)$ significance, respectively. 
participants, 15 (29.4\%) did not have access to animal health services.

In the current study, out of total 93 nonparticipants, 24 (25.8\%) of them got access to animal health services and 69 (74.2\%) did not get access to animal health services. There is an association between access to animal health services and participation in improved sheep production. Farmers during focus group discussions and at key informants' level confirmed that there was a shortage of health posts and animal health officers. It was observed that only one animal health expert was assigned for three kebeles during the survey. For this reason, farmers complained about inappropriate and inadequate animal health services. Also, focus group participants explained that the experts focused on larger ruminants than small ruminants like sheep.

Unfortunately, those participating in improved sheep production were having animal health services from different sources such as nongovernmental organizations, research centers (Areka research center branch), and community-based breed selection cooperatives. The accessibility of health services influenced smallholder farmers' participation significantly. This result is similar to Getachew et al. [19], and the health accessibility influenced the participation in improved sheep production significantly at a $1 \%$ significance level $\left(\chi^{2}=27.176\right.$, $p \leq 0.01)$. Moreover, it is in line with Pulina et al. [43] who have specified that animal health services encourage farmers to participate in improved sheep production significantly.

3.2.3. Membership of Cooperatives. As indicated in Table 5, the existence and operation of institutions such as cooperatives for marketing, saving, and credit can enhance the livelihood of smallholder farmers and be alternative sources of information, knowledge, and credit to members. Out of 51 participants, 38 (74.5\%) have membership of cooperatives and 13 (25.5\%) are not members of any cooperatives. Out of 93 participants, nonparticipants were $68(73.1 \%)$ and they were not members of any cooperative organization, whereas only $25(26.9 \%)$ were members of cooperatives. This study result has shown that membership of cooperatives plays a significant role at $1 \%$ significance level $\left(X^{2}=30.361, p \leq 0.01\right)$, which influenced the participation of smallholder farmers in improved sheep production, and similar to the study of Yin et al. [44] membership of cooperatives is one way of transferring knowledge and getting credit for production, which influences the participation of farmers positively and significantly.

3.2.4. Credit Participation. In situations where the financial capacity of an individual can limit the expansion of production activities, participating in credit from any source influenced new technology practices. As described in Table 5, in the study area, out of 51 participants on improved sheep producers, $40(78.4 \%)$ participated in credit from any of the organizations. But, out of 51 participants, 11(21.6\%) did not utilize credit from any organizations.

Out of 95 nonparticipants, 30 (32.3\%) did utilize credit but did not participate in improved sheep production. This result has shown that credit participation had a strong association with participation in improved sheep production and there was a significant relationship that exists at a $1 \%$ significance level $\left(X^{2}=28.110, p \leq 0.01\right)$. According to focus group discussions and key informants' responses, the credit utilization difference between participants and nonparticipants was due to the presence of different governmental and nongovernmental organizations that facilitated the saving and credit associations, mainly among participants.

However, the majority of respondents criticized the OMO microfinance service for its high interest rate, inability to procure the loan despite their request, and lack of other lending institutions as an alternative. This result is in line with Silong [45] who states that participation in credit can influence the adoption of new agricultural technology positively and significantly.

\subsection{Descriptive Statistics Analysis Results for Continuous Variables}

3.3.1. Age of Household Head. Table 6 has shown that the average ages of participants and nonparticipants were 44.53 and 61.27 years, respectively. This has indicated that the younger age group was the one who participated more than the older ones. Youngsters were better capable of managing assets and are more productive than older-aged households. The age variances were 6.775 and 4.564 between participants and nonparticipants, respectively. This indicates that the households who participated in improved sheep production had younger people than the nonparticipants. The age variation among nonparticipants was very low compared to participants. In another way, elders were at a similar age level. The age influenced participation significantly at a $1 \%$ significance level $(t=17.642, p \leq 0.01)$. This result is in line with the study of Bhattarai et al. [46] and stated that the level of innovativeness in agricultural technology adoption is lower among older farmers.

3.3.2. Educational Status of Household Heads. As indicated in Table 6, the educational level of respondents' mean grades of participants and nonparticipants were 5 and 2, respectively. Household heads with a high level of education participated in improved sheep production, more than those who had less educational level. Education has a relationship with participation at 5\% significance level $(t=17.404$, $p<0.05)$. The variations of education level were 1.568 and 1.027 among participants and nonparticipants, respectively. This means variation among nonparticipants was very less (nonparticipants achieved similarly lower grades).

Hence, the data analysis showed that a high level of education had a significant association with the trends of participating in improved sheep production. This finding is in line with Tegegne [47] who found that educated households tend to have higher productivity, use of information, and are able to adopt new production techniques than the less educated households.

3.3.3. Distance from Kebele Center. Distance from the kebele center to their home plays a vital role in rural communities in case of knowledge exchange at the kebele (farmers training 
TABLE 6: Descriptive statistics' results of continuous explanatory variables.

\begin{tabular}{|c|c|c|c|c|c|c|}
\hline \multirow{2}{*}{ Variable } & \multicolumn{2}{|c|}{ Participants } & \multicolumn{2}{|c|}{ Nonparticipants } & \multirow{2}{*}{$P$ value } & \multirow{2}{*}{$T$ value } \\
\hline & Mean & Stand. Dev & Mean & Stand. Dev. & & \\
\hline Age in year (AGE cont) & 44.53 & 6.775 & 61.27 & 4.564 & 0.002 & $17.642^{* * *}$ \\
\hline Educational status (EDU) & 5.000 & 1.568 & 2.000 & 1.027 & 0.013 & $17.407^{* *}$ \\
\hline Distance from Kebele center (DFKC) & 1.180 & 0.478 & 2.91 & 0.351 & 0.014 & $24.927^{* *}$ \\
\hline Land size (LAND cont) & 1.120 & 0.448 & 0.750 & 0.264 & 0.001 & $6.179^{* * *}$ \\
\hline Farm income $(\mathrm{FI})$ & 9627.45 & 2999.739 & 6105.38 & 2079.839 & 0.004 & $8.272^{* * *}$ \\
\hline Off-farm income (NFI) & 2196.08 & 626.725 & 1066.77 & 466.679 & 0.001 & $12.261^{* * *}$ \\
\hline Household labor in ME (HHLME) & 4.980 & 1.295 & 2.36 & 0.602 & 0.0001 & $16.641^{* * *}$ \\
\hline Distance from near market center to their home (DFNMC) & 4.450 & 1.487 & 6.000 & 1.707 & 0.328 & $5.444 \mathrm{NS}$ \\
\hline Frequency of development agents contact (FDC) & 37.290 & 2.773 & 14.77 & 6.478 & 0.0001 & $23.639^{* * *}$ \\
\hline
\end{tabular}

Source: computed from own survey data, $2018{ }^{* * *},{ }^{* *}$, NS shows significance level at $1 \%, 5 \%$, not significant, respectively.

center). The result of the study, as indicated in Table 6 , shows that the average distance between participants and nonparticipants were 1.18 and 2.91 kilometers, with a standard deviation of 0.478 and 0.351 , respectively. This indicated that most of the participants lived around the kebele's center compared to nonparticipants, and the variation of distances among them has shown that those farmers who lived far away were ignored.

Generally, the farmers who live far from the kebele's center faced the problem of participation in improved sheep production. In this study, distance from the kebele center influenced the participation significantly at a $5 \%$ significance level; $t=24.927 ; p<0.05)$. Brown et al. [9] reported a similar relationship between distance from the kebele and participation in improved livestock technology in the Dejen district.

3.3.4. Size of Landholding. Responses of focus group discussions implied that most of the smallholder farmers in the study area use their land only for all farming activities, which include production of food crops and cash crops, house construction, tethering livestock during the rainy season, and tree planting. The sampled households did not get extra land even for renting.

As described in Table 6, the mean land holding of participants and nonparticipants in the study area was $1.12 \mathrm{ha}$ and $0.75 \mathrm{ha}$, respectively, and a standard deviation of 0.448 and 0.264 , respectively. This has shown that there was a significant difference among participants and nonparticipants, and nonparticipants had similarly very low landholdings. Landholding affected participation at $1 \%$ significance level $(t=6.179 ; p \leq 0.01)$. This trend is similar to the South Nations, Nationalities, and People's Region where $81.8 \%$ of the households own less than one hectare and only $3.8 \%$ of the farming households own greater than 2 ha (Teffera et al.) [48], which could be due to variations in the population density.

3.3.5. Farm Income of the Household. Households' farm income is one of the important factors determining the adoption of improved technologies. The amount of household income obtained from the sale of crops and livestock after the household consumption requirement could be used for the purchase of farm inputs. Improved sheep production often requires intensive input which has great implications on the cost of production. Due to this, improved sheep production needs to have the required amount of income from their agricultural activities to run the improved sheep production activities. According to Table 6 , the average annual farm income of the participating and nonparticipating sample households was 9627.45 and 6105.38 birr as well as a standard deviation of 2999.739 and 2079.839, respectively.

In the current research, the farm income variation between participants and nonparticipants group indicated that nonparticipants groups has less farm income as compared to the participant groups. In this study, agricultural income influenced participation positively at a $1 \%$ significance level $(t=8.272, p \leq 0.01)$. Therefore, a household with relatively higher farm income was expected to better adopt an improved sheep production package and it is in line with the study of Olson, [49].

3.3.6. Households' Off-Farm Income in a Production Year. Households' income sources in rural areas are as diverse as households' activities even within the agricultural sector. Table 6 has shown that the annual off-farm incomes among participants and nonparticipants were 2196.08 and 1066.77 ETB, respectively, and standard deviations among each other were 626.725 and 466.679, respectively. Based on Focus Group Discussion (FGD), most of the farmers who get remittances from abroad and from different sources in the country were more likely to participate in improved sheep production. The households who had better off-farm income had a higher probability of participating in improved sheep production and affected participation significantly at a $1 \%$ significance level $(t=12.261 ; p \leq 0.01)$. It is in consonance with the study of Asante et al. [50] that off-farm income enables farmers to purchase new agricultural technology.

3.3.7. Household Labor. The overall mean of family labor size in man equivalent for sheep producers was 4.98 and 2.36 for participants and nonparticipants, respectively, and the variation of labor size for participant and nonparticipant labor was 1.295 and 0.602 , respectively. Table 6 has indicated there were very few variations of labor size among 
nonparticipants compared to participants (nonparticipant households had similarly less labor among them). The result of test statistics has shown that the availability of labor influenced participation significantly at $1 \%$ significance level $(t=16.553, p \leq 0.01)$.

According to focus group discussions and key informants, a household with a large working labor force was in a position to manage the labor-intensive agricultural activities, including livestock production such as rearing and watering activities that are accomplished by boys and girls. Tethering, providing feeds, cleaning the shed are activities of women and children while taking to medication are the responsibilities of adult men and women. Selling and purchasing of sheep are the responsibilities of the owner, who in most instances the head of the household. The findings are in agreement with those of Cafer and Rikoon [51], who reported that the described availability of enough labor in the family is expected to be significantly and positively related to the adoption of improved agricultural technology.

3.3.8. Distance from near Market Center to Their Home (DFNMC). Distance from near the market center plays a vital role in rural communities in case of market information exchange. The result of the study indicates in Table 6 that the average distances between participants and nonparticipants were 4.45 and 6 kilometers, and standard deviations were 1.487 and 1.707, respectively. The result indicates that participants living far from the markets' center faced the problem of not having updated market information and participated less in improved sheep production compared to the one who lives near the market. But, it is not significantly associated with participation $(t=5.444 ; p>0.05)$. The focus group discussion responses state that even though the market problem was common, this area has not had a serious problem of market access.

3.3.9. Frequency of Contact with Development Agents. Extension contact is supposed to have a direct influence on the behavior of farmers to intensify and improve their production through resolving problems and improving efficiency to make use of opportunities. When there is contact with extension agents (DA), there is a greater possibility of farmers being influenced to adopt agricultural innovations and improve their productivity.

In Table 6, the average contact with development agents for participants and nonparticipants was 37.29 and 14.77 with a standard deviation of 2.773 and 6.478 , respectively. This implied that participants made a lot of contacts with development agents with the very minimum differences among each other compared to nonparticipants. It affected significance at $1 \%$ level $(t=23.639, p \leq 0.01)$; this finding is in line with the study of Vince et al. [52], which has indicated that the livestock production systems require knowledge change according to contact with extension workers.

3.4. Results of the Econometric Model/Logit. The previous section mainly had dealt with descriptions of the sample population and tests of the association between the dependent and explanatory variables using the chi-square and $t$-tests. However, identification of these factors alone is not enough to stimulate policy actions unless the relative influence of each factor is known for priority-based intervention. In this section, an econometric model (binary logit) was used to see the relative influence of different demographic, socioeconomic, and institutional variables on the participation of farm households in improved sheep production.

Determinants that had a significant relationship with the dependent variable were included in the Logit model. Generally, twelve out of thirteen variables that had a significant relationship with the dependent variables during descriptive statistics analysis were included in the binary logit model. Before running the binary logit model, all the hypothesized explanatory variables were checked for the existence of a multicollinearity problem. Contingency coefficients were computed for discrete variables and described in Table 3. Similarly, the VIF values diagnosed to check the multicollinearity of continuous variables are displayed in Table 4 . In both cases, variables have no strong collinearity problem. Based on the above test, both the hypothesized continuous and discrete variables were included in the model.

\subsubsection{Determinants of Participation in Improved Sheep} Production. Estimates of the parameters of the variables expected to determine the participation of improved sheep production are displayed in Table 7 . From the total of thirteen potential explanatory variables, twelve were incorporated into the econometric model out of which the following seven variables influenced the participation of smallholder farmers in improved sheep production significantly, namely, labor size (HHLME), age (AGE), frequency of contact with development agents (FDC), membership of cooperatives (MSC), land size (LANDSZ), credit utilization (CU), and off-farm income (OFI). They are discussed in the following paragraphs.

(1) Labor Availability. Participation in improved sheep production requires adequate labor supply to carry out the production processes. It was hypothesized that the availability of labor positively influences participation in improved sheep technology. The finding of this study was similar to the hypothesis that described that the size of household labor (HHLME) influenced the participation of smallholder farmers in improved sheep production significantly and positively at $1 \%(p<0.01)$. When labor increases by units, participation increases by an odds ratio of (12.061) or by a $6.1 \%$ probability level. Thus, households with large family sizes tend to improve their participation in the production of improved sheep. It is similar to the findings of Lima et al. [53], who reported that labor affects new technology adoption, production, and productivity significantly and positively.

(2) Age. The result of the study shows that the age of the household head influenced participation in improved sheep 
production negatively at $5 \%(p<0.05)$. This is different from the hypothesis of this study. When age increased by a year, participation in improved sheep production decreased by odds of 3.466 or by a probability level of $47 \%$. This is a fact indicated by focus group discussions and key informants in the study area, as older people fear risk because sheep production involves high risks like heavy management tasks, fear of serious respiratory diseases, and feed shortage. These were some possible reasons for the negative relationship between the age of the household head and participation in improved sheep production. This result of the current study is in line with the study of Bhattarai et al. [46] who reported that the level of innovativeness was found to be lower among older farmers.

Also, this finding is in consonance with a study conducted by Danso-Abbeam et al. [54] on the adoption of improved livestock technology which has reported that younger farmers were more likely to adopt and the effect of age on the probability of adoption was elastic. Moreover, Gunte [55] found that smallholders' adoption of small ruminants in the South-Eastern highlands of Ethiopia reported that age had a negative effect on the adoption of new technology.

(3) Frequency of Extension Contact. Development agents visit farmers and would enable the farmers to develop a positive attitude towards participation in improved sheep production. The finding was similar to the hypothesis of this study which implied that contact with development agents personally as well as engaging them in field days and training influenced positively and significantly at $1 \%$ $(p \leq 0.01)$. The odds ratio (1.019) indicates that the participation in improved sheep production increases by a factor of 1.019 or by a $2 \%$ probability level as the result of one unit increase of the extension contact for the households. This finding is consistent with the findings of Vince et al. [52] which has indicated that the livestock production systems require knowledge change through contacting extension workers.

(4) Membership of Cooperatives. Cooperatives are one of the important organizations in rural and agricultural development which serve as an important source of information, knowledge transfer, and rural credit. In this study, similar to the hypothesis, participation in cooperatives had a significant and positive influence on the participation of smallholder farmers in improved sheep production at $1 \%(p \leq 0.01)$, and the probability of cooperative members participation in improved sheep production increased by odds of 21.802 or by $80 \%$ probability level as compared to nonmembers of the cooperative. It is in line with Fufa [56], who reported that organizing farmers in a cooperative society would facilitate access to credit, extension information, and market. This implies being a member of rural cooperatives can enhance the adoption of new agricultural technology.

(5) Land Owned by Households. Results showed that respondents' less participation in improved sheep production was due to scarcity of rangelands. Similar to the hypothesis of this study, the result of this study has shown that land size influenced participation decisions in improved sheep production significantly and positively at a $1 \%$ significance level $(p \leq 0.01)$. When land increases by one hectare, the probability of participation increased by odds of 29.283 or by a $28 \%$ probability level.

The data gathered qualitatively from focus group discussions and key informants assured that participants had more land compared to nonparticipants in the study area and thus, nonparticipants keep their sheep more frequently under stall feeding or cut and carry system, and also use more of other types of feed such as supplements and expensive industrial by-products. It is in line with Mishra et al. [57] who reported that land is a very crucial input for livestock production and that it can influence the production of improved livestock production significantly and positively.

(6) Credit Participation. This is a very important determinant for households' decision to take more risks and enhance their financial capacity to purchase inputs that complements the package of sheep technologies, improved breed purchasing, veterinary purpose, and other management activities. In this study, credit participation was similar to the hypothesis and was influenced significantly and positively at a $5 \%$ significant level $(p<0.05)$. The probability of participation in improved sheep production increased by odds of 10.026 or by a $3 \%$ probability level as compared to nonparticipants of credit. Participation in credit affects an improvement of participation in livestock technology production positively and significantly, and this is in consonance with the finding of Silong [45].

(7) Off-Farm Income. Households' income position and resource ownership were found to be important determinants in the participation of improved sheep production. Similar to the hypothesis, the result of this study indicated that households who had better off-farm income from different sources participated well compared to those who did not get access to off-farm income. It influenced the participation of smallholder farmers in improved sheep production positively and significantly at $1 \% p \leq 0.001)$. When off-farm income increased by one thousand ETB, the probability of participation increased by odds of 1.002 or by a $0.2 \%$ probability level. This means that a farmer who had better off-farm income from different sources was more likely to adopt improved sheep production. This is in line with a study conducted by Mwangi and Kariuki [58], who reported that petty trades, daily labor on others' farms, and nonfarm activities as well as small businesses enable farmers to get additional income to have production inputs and can influence positively and significantly new agricultural technology adoption.

3.5. Impact of Participation in Improved Sheep Production on Smallholder Farmers' Income. Sheep is one of the most affordable animals in the world and can be accommodated in 
TABLE 7: The results of the binary logit model.

\begin{tabular}{|c|c|c|c|c|c|}
\hline Variable & (B) & S.E & Wald statistics & Sig. Level & $\operatorname{Exp}(\mathrm{B})$ \\
\hline Household labor in ME & 2.49 & 0.679 & 13.51 & $0.001^{* * *}$ & 12.061 \\
\hline Age of the rural farm household head (AG) & -1.243 & 0.589 & 4.456 & $0.035^{* *}$ & 3.466 \\
\hline Sex of the household head (SEX) & -0.242 & 1.092 & 0.049 & 0.824 & 1.274 \\
\hline Frequency of extension contact (FDC) & 0.019 & 6 & 11.552 & $0.001^{* *}$ & 1.019 \\
\hline Education level of household head (EDU) & 0.395 & 0.322 & 1.501 & 0.220 & 1.484 \\
\hline Membership of cooperatives (MSC) & 3.082 & 1.147 & 7.215 & $0.007^{* * *}$ & 21.802 \\
\hline Size of land in hectares (LAND SZ) & 3.377 & 1.171 & 8.324 & $0.004^{* * *}$ & 29.283 \\
\hline Credit participation $(\mathrm{CP})$ & 2.305 & 1.119 & 4.24 & $0.039^{* *}$ & 10.026 \\
\hline Farm income $(\mathrm{FI})$ & 0.000 & 0.000 & 0.705 & 0.401 & 1.000 \\
\hline Distance from market (DTNMC) & 0.330 & 1.173 & 0.079 & 0.779 & 1.391 \\
\hline Off-farm income (OFI) & 0.002 & 0.001 & 8.596 & $0.003^{* * *}$ & 1.002 \\
\hline Access to animal health service (AHS) & 5.821 & 0.606 & 5.537 & 0.217 & 333.309 \\
\hline
\end{tabular}

Number of Obs. $=144 ; p \leq 0.001$; Nagelkerke $R$ Square $=78.947$. Notes: $\operatorname{Exp}(B)$ shows the predicted changes in odds for a unit increase in the predictor; ${ }^{* *}$ and *** significant at $5 \%$, and $1 \%$ levels (source: computed from own survey data, 2018).

TABLE 8: Farm income of smallholder farmers in 2017.

\begin{tabular}{lcccr}
\hline \multirow{2}{*}{ Variable } & \multicolumn{2}{c}{ Participants } & \multicolumn{2}{c}{ Nonparticipants } \\
& Mean & Stand. Deviation & Mean & Stand. Deviation \\
\hline Farm income & 9627.45 & 2999.74 & 6105.38 & 2079.84 \\
Income from sheep production & 3447.06 & 1584.34 & 1380.65 & 230.43 \\
\hline
\end{tabular}

Source: computed from own survey data, $2018 ;{ }^{* * *}=1 \%$ significance level.

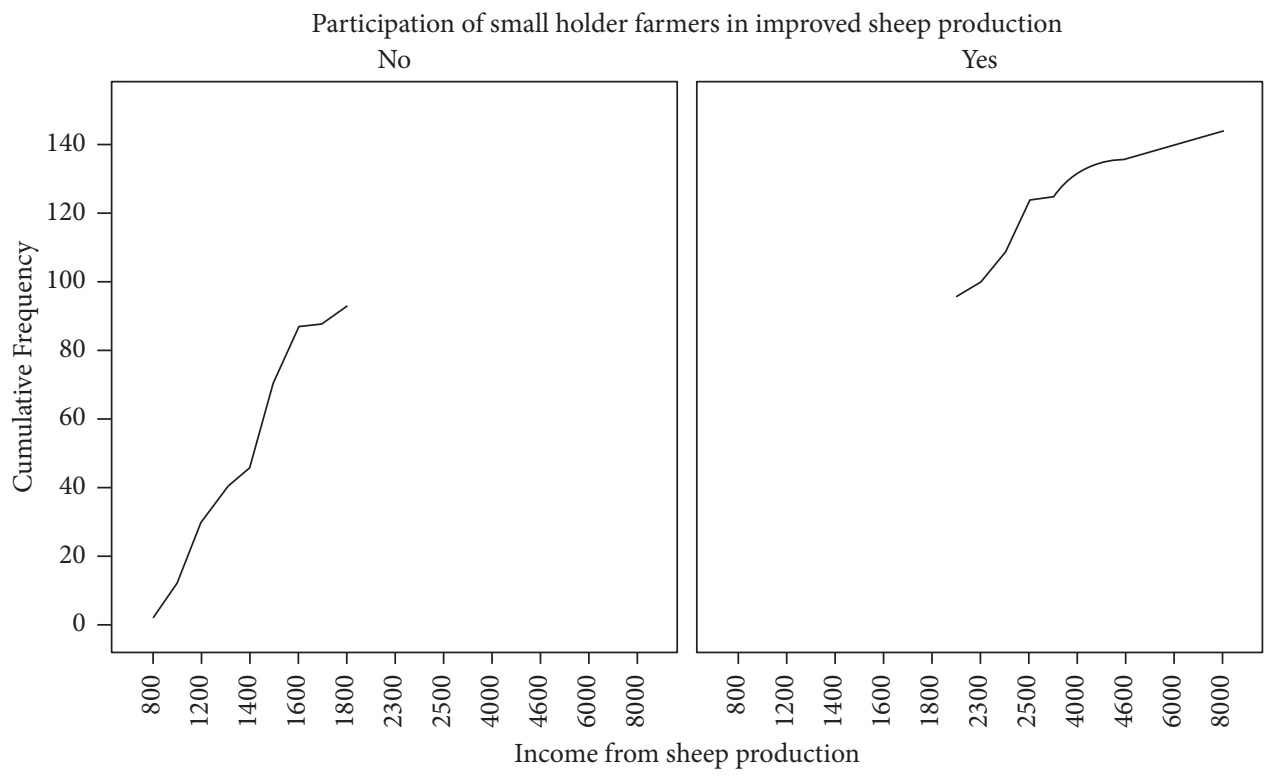

Figure 2: The farm income of participant and nonparticipant smallholder farmers (source: computed from own survey data, 2018).

any kind of weather condition. They are also called poor man's cows, and rearing sheep contributes a lot to the economy by generating household income, providing local employment, and export [59].

According to the survey results, the average farm income of participants and nonparticipants were 9627.45 and 6105.38 ETB with a standard deviation of 2999.74 and 2079.84, respectively. Generally, farm income differences between participants and nonparticipants of improved sheep producers were significant. Both focus group discussions and key informants' data confirmed that the income source of smallholder farmers is mainly farming (both livestock and crop), but the sheep production due to its potential in the area made a great difference in smallholder household income.

Sheep production is increasing constantly in the study area, due to the constant decrease of arable land as well as the trend of improving the genotype of sheep (improving breed) at the community level, which initiates smallholder farmers (there is community-based improved breed selection 


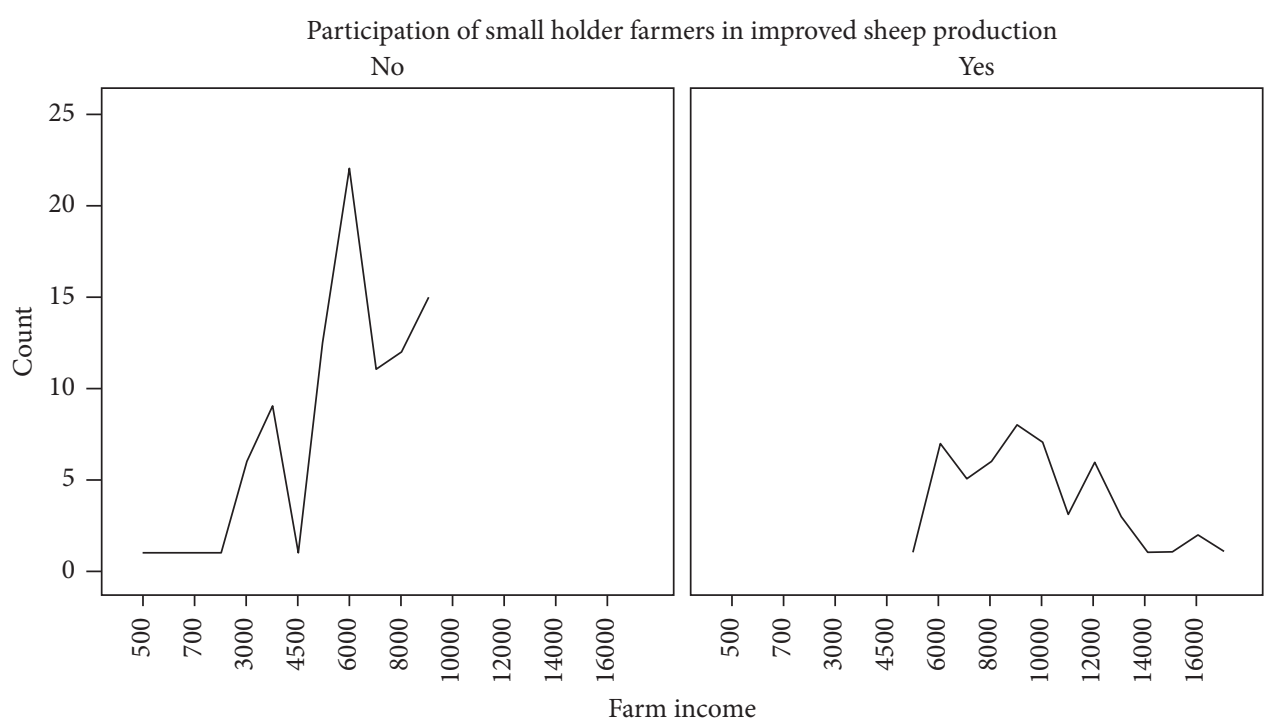

FiguRE 3: The income of participant and nonparticipant smallholder farmers from sheep production. (source: computed from own survey data, 2018).

practice by different stakeholders). As described in Table 8, the average income from sheep production was 3447.06 and 1380.65 ETB with a standard deviation of 1584.34 and 230.43 for participants and nonparticipants, respectively. It has shown that participants' average income was 3447.06 ETB, but in the case of nonparticipants it was only 1380.65 ETB. Hence, there is a difference of 2066.41 ETB between participants and nonparticipants.

Generally, participants of focus group discussions and key informants suggested that the impact of participation in improved sheep production was significant and made a difference among smallholder farmers' living styles.

As described in Figure 2, average income gained from sheep production in the case of participants' income obtained from sheep production ranges from 1,800 to 6,000 ETB, whereas nonparticipants' income ranged from 800 to 1,800 ETB. This implies that participants gained better income from their sheep production compared to nonparticipants in improved sheep production. Based on the response to focus group discussions and key informant data, this income difference is due to better market and financial support for participants from governmental and nongovernmental organizations as well as technical support from Areka research center branch at Doyogena. Again, they suggested that sheep production needs both technical and financial support, so such reasons contributed to the income difference between participants and nonparticipants.

As shown in Figure 3, the farm income (which was obtained both from livestock and crop) ranged from 4500 to 17,000 and 500 to 10,000 ETB for participants and nonparticipants, respectively. Most of the participants obtained much income from sheep production due to the short-term reproduction rate, early weaning of weight, better price of the improved breed, and weighing sell trend for improved sheep in the study area. This result was confirmed by focus group discussions; the farmers in the study area have almost the same land size but the ones who participated in improved sheep production earn more income due to peculiar characteristics of the Doyogena sheep breed (shortterm reproduction rate, early weaning of weight, and better physical appearance), and it mostly favors the higher productivity of participants in improved sheep production. It is in line with the study of Legese et al. [60] who reported that improving the sheep breed can enhance productivity as well as the livelihood of smallholder farmers.

Also, participants of focus group discussions clarified that improved sheep production showed a significant impact on the livelihood of smallholder farmers. Most households in the study area had short-term income as these smallholder farmers were challenged to cover food costs, education fees, clothes, and agricultural inputs. However, the living style of those who participated in improved sheep production has been changed, and it enables them to cover such costs easily compared to nonparticipants.

\section{Conclusion}

The expected output of the research was identifying the most likely determining factors, income contribution, and challenges related to improved sheep production regardless of smallholder farmers. In this study, 100 males and 44 females were included' out of a total of 144 samples, 51 (35.4\%) sheep producers participated in improved sheep production. All variables have a significant relationship with participation except distance from the near market center. Determinants that significantly limited participation of smallholder farmers in improved sheep production in the study area were labor, age, frequency of contact with development agents, land size, off-farm income, membership of cooperatives, and participation in credit. According to survey results and focus group discussion responses, the households which had large size labor undertook these activities than those that had a small size of labor and participated well in improved sheep production simultaneously. 
Based on focus groups and key informants' responses, aged farmers feared risk and management activities of improved sheep production, because of the shortage of communal land for free grazing (the only means of feeding sheep was carry and cut system), and housing was also another challenge for elders. Another determinant that influenced participation was land size owned by households which affected significantly and positively; farmers who owned large tracts of land for free grazing, producing improved fodders, housing, and other management practices participated in improved sheep production better than the ones that had small-size landholdings.

The impact of participation in improved sheep production on the economy of smallholder farmers' income was identified. Income of smallholder households that participated in improved sheep production was enhanced, and it fetched them 2066.41 additional ETB compared to nonparticipants. This amount of money regardless of the type of farmers was very high and made a difference in their living style. Thus, the future effort through an effective policy should be intended to accelerate agricultural and rural development through effective utilization of improved sheep potential regarding smallholder farmers in the study area particularly, and in Ethiopia generally.

\section{Abbreviations}

CSA: Central Statistics Authority

OMO: Type of Microfinance

PISP: $\quad$ Participating in Improved Sheep Production

NPISP: Not Participating in Improved Sheep Production

SNNPRS: Southern Nations, Nationalities, and People's Region.

\section{Data Availability}

The data will be provided upon the request of the corresponding author.

\section{Consent}

Not applicable.

\section{Conflicts of Interest}

All authors declared no competing conflicts of interest.

\section{References}

[1] Central Statistical Agency, "Federal democratic republic of Ethiopia," in The 2015/16 National Statistics, Agricultural Sample Survey, Addis Ababa, Ethiopia, 2015.

[2] Z. Edea, T. Dessie, H. Dadi, K.-T. Do, and K.-S. Kim, "Genetic diversity and population structure of Ethiopian sheep populations revealed by high-density SNP markers," Frontiers in Genetics, vol. 8, p. 218, 2017.

[3] A. Varga, Z. Molnár, M. Biró et al., "Changing year-round habitat use of extensively grazing cattle, sheep and pigs in East-Central Europe between 1940 and 2014: consequences for conservation and policy," Agriculture, Ecosystems \& Environment, vol. 234, pp. 142-153, 2016.
[4] H. Desta, Gendered Priority Livestock Species and Roles in Small Ruminant Production, CRP Livestock and IFAD, Addis Ababa, Ethiopia, 2017.

[5] A. Lakew, A. Melesse, and S. Banerjee, "Traditional sheep production systems and breeding practice in Wolayita Zone of Southern Ethiopia," African Journal of Agricultural Research, vol. 12, no. 20, pp. 1689-1701, 2017.

[6] G. Gebrehiwot, T. Negesse, and A. Abebe, "Effect of feeding leucaena leucocephala leaves and pods on feed intake, digestibility, body weight change and carcass characteristic of central-highland sheep fed basal diet wheat bran and natural pasture hay in tigray, Ethiopia," International Journal of Agriculture Environment \& Biotechnology, vol. 10, no. 3, pp. 367-376, 2017.

[7] S. Gizaw, A. Abebe, A. Bisrat, T. Zewdie, and A. Tegegne, "Defining smallholders' sheep breeding objectives using farmers trait preferences versus bio-economic modelling," Livestock Science, vol. 214, pp. 120-128, 2018.

[8] G. R. Gowane, Y. P. Gadekar, V. Prakash, V. Kadam, A. Chopra, and L. L. L. Prince, "Climate change impact on sheep production: growth, milk, wool, and meat," Sheep Production Adapting to Climate Change, Springer, Berlin, Germany, 2017.

[9] M. E. Brown, "A climate trend analysis of Ethiopia: examining sub-seasonal climate impacts on crops and pasture conditions," Climatic Change, vol. 142, no. 1-2, pp. 169-182, 2017.

[10] T. F. A. M. Ahmed, Socio-Economic Aspects of Sheep Preding for Productive Families in Blue Nile State-Sudan, Sudan University of Science and Technology, Khartoum, Sudan, 2016.

[11] K. Tindano, N. Moula, P. Leroy, A. Traoré, and N. AntoineMoussiaux, "Market organization and animal genetic resource management: a revealed preference analysis of sheep pricing," Animal, vol. 11, no. 10, pp. 1873-1880, 2017.

[12] O. A. Oladunni and J. J. Aduba, "Household income generation, progression and sustainability under Fadama III implementation," Research Journal of Agriculture and Environmental Management, vol. 3, no. 8, pp. 406-416, 2014.

[13] Central Statistical Agency, "Report on livestock and livestock characteristics," The Federal Democratic Republic of Ethiopia, Private Peasant Holdings, Statistical Bulletin 570, CSA, Addis Ababa, Ethiopia, 2017.

[14] Y. Dagnew, M. Urge, Y. Tadesse, and S. Gizaw, "Sheep production and breeding systems in north western lowlands of Amhara region, Ethiopia: implication for conservation and improvement of Gumz sheep breed," Open Journal of Animal Sciences, vol. 7, no. 2, pp. 179-197, 2017.

[15] DDLFO, Doyogena District Livestock and Fishery Office. 1st Term Report, Kembata Tembaro Zone, South Nation Nationalities and Peoples Republic (SNNPR), Addis Ababa, Ethiopia, 2018.

[16] C. Aydin, P. G. Tibbo, and Z. Ursuliak, "Psychosocial interventions in reducing cannabis use in early phase psychosis," Canadian Journal of Psychiatry, vol. 61, no. 6, pp. 367-372, 2016.

[17] B. T. Kassa, A. G. Haile, and J. A. Essa, "Determinants of sheep prices in the highlands of northeastern Ethiopia: implication for sheep value chain development," Tropical Animal Health and Production, vol. 43, no. 8, pp. 1525-1533, 2011.

[18] H. Tesfay, A. Banerjee, and Y. Mummed, "Morphological characterization of indigenous sheep population in their production system for developing suitable selection criteria in central zone of Tigray, Northern Ethiopia," International Journal of Livestock Production, vol. 8, no. 4, pp. 40-47, 2017. 
[19] T. Getachew, B. Alemu, J. Sölkner et al., "Relative resistance of Menz and Washera sheep breeds to artificial infection with Haemonchus contortus in the highlands of Ethiopia," Tropical Animal Health and Production, vol. 47, no. 5, pp. 961-968, 2015.

[20] S. Gizaw, T. Getachew, S. Goshme et al., "Efficiency of selection for body weight in a cooperative village breeding program of Menz sheep under smallholder farming system," Animal, vol. 8, no. 8, pp. 1249-1254, 2014.

[21] DDANRO, Doyogena District Agricultural and Natural Resources Office. 1st Round Report, DDANRO, Kembata Tembaro Zone, Ethiopia, 2017.

[22] DDFEDO, District Finance and Economy Development Office. 2nd Term Final Report, SNNPR, Kembata Tembaro Zone, Ethiopia, 2017.

[23] T. Yamane, Statistics: An Introductory Analysis, Harper and Row, New York, NY, USA, 1967.

[24] D. Gujarati, Basic Econometrics, McGraw-Hill, New York, NY, USA, 3 edition, 1995.

[25] A. Braimllari and E. Sala, "An econometric analysis of online ratings of hotels in Albania," in Proceedings of 13th International Conference of ASECU Social and Economic Challenges in Europe, Durres, Albania, May 2017.

[26] M. J. Crowder and D. J. Hand, Analysis of Repeated Measures, Vol. 41, CRC Press, Boca Raton, FL, USA, 1990.

[27] D. P. Kothari, "Power system optimization," in Proceedings of 2nd National Conference on Computational Intelligence and Signal Processing (CISP)IEEE, Guwahati, India, March 2012.

[28] N. Assan, "Micro-livestock farming and food security in subSaharan Africa," Journal of Animal Production Advances, vol. 4, no. 4, pp. 374-387, 2014.

[29] T. Urgessa, "The determinants of agricultural productivity and rural household income in Ethiopia," Ethiopian Journal of Economics, vol. 24, no. 2, pp. 63-91, 2015.

[30] J. H. Mathebula, Determinants of Household Participation in Agricultural Production in Shatale Region of the Bushbuckridge Local Municipality, University of Limpopo, Mpumalanga Province, South Africa, 2015.

[31] D. Haile, S. Gizaw, and K. Kefelegn, "Selection criteria and breeding practice of sheep in mixed crop-livestock farming system of North Shoa, Ethiopia," Journal of Biology, Agriculture and Healthcare, vol. 5, no. 21, pp. 168-174, 2015.

[32] J. P. Mueller, B. Rischkowsky, A. Haile et al., "Communitybased livestock breeding programmes: essentials and examples," Journal of Animal Breeding and Genetics, vol. 132, no. 2, pp. 155-168, 2015.

[33] S. Rasch, T. Heckelei, and R. Johannes Oomen, "Reorganizing resource use in a communal livestock production socioecological system in South Africa," Land Use Policy, vol. 52, pp. 221-231, 2016.

[34] R. Babatunde, O. Ayinde, F. Oladipo, and A. Adekunle, "Determinants and effect of livelihood diversification among small-scale poultry farmers in Oyo State, Nigeria," Ethiopian Journal of Environmental Studies and Management, vol. 8, no. 1, pp. 782-791, 2015.

[35] E. G. Kebebe, "Understanding factors affecting technology adoption in smallholder livestock production systems in Ethiopia: the role of farm resources and the enabling environment," in Graduate School of Wageningen, Institute of Animal Sciences (WIAS)Wageningen University, Wageningen, NL, USA, 2015.

[36] T. Hennessy and K. Heanue, "Quantifying the effect of discussion group membership on technology adoption and farm profit on dairy farms," The Journal of Agricultural Education and Extension, vol. 18, no. 1, pp. 41-54, 2012.

[37] T. T. Deressa, R. M. Hassan, and C. Ringler, "Perception of and adaptation to climate change by farmers in the Nile basin of Ethiopia," The Journal of Agricultural Science, vol. 149, no. 1, pp. 23-31, 2011.

[38] A. Elias, "Farmers' satisfaction with agricultural extension service and its influencing factors: a case study in North West Ethiopia," Journal of Agricultural Science and Technology A, vol. 18, no. 1, pp. 39-53, 2016.

[39] T. P. Robinson, D. P. Bu, J. Carrique-Mas et al., "Antibiotic resistance: mitigation opportunities in livestock sector development," Animal, vol. 11, no. 1, pp. 1-3, 2017.

[40] A. Mohammed, D. Woldeyohannes, A. Feleke, and B. Megabiaw, "Determinants of modern contraceptive utilization among married women of reproductive age group in North Shoa Zone, Amhara Region, Ethiopia," Reproductive Health, vol. 11, no. 1, p. 13, 2014.

[41] A. Hagos and L. Zemedu, "Determinants of improved rice varieties adoption in Fogera district of Ethiopia," Science, Technology and Arts Research Journal, vol. 4, no. 1, pp. 221228, 2015.

[42] E. Musgrave, "Women and the craft guilds in eighteenthcentury Nantes," in The Artisan and the European Town, 1500-1900Routledge, Milton Park, UK, 2016.

[43] G. Pulina, M. J. Milán, M. P. Lavín et al., "Invited review: current production trends, farm structures, and economics of the dairy sheep and goat sectors," Journal of Dairy Science, vol. 101, no. 8, pp. 6715-6729, 2018.

[44] Y. Yin, Z. Wang, X. Li et al., "Factors affecting herder adoption of winter lambing practices in the desert steppe region of Inner Mongolia, China," The Rangeland Journal, vol. 40, no. 1, pp. $65-75,2018$.

[45] A. K. Silong, "Credit and the technical efficiency of sheep and goat production among rural female farmers in Nasarawa State, Nigeria," in School of Agriculture, Policy and DevelopmentFaculty of Life Sciences, University of Reading, Reading, UK, 2017.

[46] M. Bhattarai, A. Maskey, R. K. Sah et al., "Fractional flow reserve for intermediate coronary artery stenosis in Nepal," Nepalese Heart Journal, vol. 12, no. 2, pp. 69-72, 2015.

[47] Y. Tegegne, Factors Affecting Adoption of Legume Technologies and its Impact on Income of Farmers: The Case of Sinana and Ginir Woredas of Bale Zone, Haramaya University, Haramaya, Ethiopia, 2017.

[48] Z. L. Teffera, J. Li, T. M. Debsu, and B. Y. Menegesha, "Assessing land use and land cover dynamics using composites of spectral indices and principal component analysis: a case study in middle Awash subbasin, Ethiopia," Applied Geography, vol. 96, pp. 109-129, 2018.

[49] R. Olson, "Building sustainable agriculture: a new application of farming systems research and extension," in Integrating Sustainable Agriculture, Ecology, and Environmental PolicyRoutledge, Milton Park, UK, 2017.

[50] B. O. Asante, R. A. Villano, I. W. Patrick, and G. E. Battese, "Determinants of farm diversification in integrated croplivestock farming systems in Ghana," Renewable Agriculture and Food Systems, vol. 33, no. 2, pp. 131-149, 2018.

[51] A. M. Cafer and J. S. Rikoon, "Adoption of new technologies by smallholder farmers: the contributions of extension, research institutes, cooperatives, and access to cash for improving tef production in Ethiopia," Agriculture and Human Values, vol. 35, no. 3, pp. 685-699, 2018. 
[52] L. Vince, G. A. Kleter, K. Kostov, D. U. Pfeiffer, and J. Guitian, "The applicability of animal health surveillance systems for post-market monitoring of potential adverse effects of genetically modified (GM) feed," Food and Chemical Toxicology, vol. 117, pp. 79-88, 2018.

[53] E. Lima, T. Hopkins, E. Gurney et al., "Drivers for precision livestock technology adoption: a study of factors associated with adoption of electronic identification technology by commercial sheep farmers in England and Wales," PLoS One, vol. 13, no. 1, Article ID e0190489, 2018.

[54] G. Danso-Abbeam, E. D. Setsoafia, and I. G. K. Ansah, "Modelling farmers investment in agrochemicals: the experience of smallholder cocoa farmers in Ghana," Research in Applied Economics, vol. 6, no. 4, pp. 1-16, 2014.

[55] K. Gunte, Understanding Factors Affecting Technology Adoption in Smallholder Livestock Production Systems in Ethiopia: The Role of Farm Resources and the Enabling Environment, Wageningen University, Wageningen, Netherlands, 2015.

[56] Z. Fufa, Assessing The Contribution of Agricultural Cooperatives To Poverty Alleviation in the Case of Gechi District, St. Mary's University, Ilubabor Zone, Ethiopia, 2016.

[57] K. Mishra, A. G. Sam, and M. J. Miranda, "You are approved! Insured loans improve credit access and technology adoption of Ghanaian farmers," in Proceedings of 30th International Conference of Agricultural Economist, p. 48, Ohio State University, Vancouver, OH, USA, July, 2018.

[58] M. Mwangi and S. Kariuki, "Factors determining adoption of new agricultural technology by smallholder farmers in developing countries," Journal of Economics and Sustainable Development, vol. 6, no. 5, pp. 208-2016, 2015.

[59] R. Marino, A. S. Atzori, M. D’Andrea, G. Iovane, M. TrabalzaMarinucci, and L. Rinaldi, "Climate change: production performance, health issues, greenhouse gas emissions and mitigation strategies in sheep and goat farming," Small $\mathrm{Ru}$ minant Research, vol. 135, pp. 50-59, 2016.

[60] G. Legese, Sheep and Goat Value Chains in Ethiopia: A Synthesis of Opportunities and Constraints, International Livestock Research Institute (ILRI), Addis Ababa, Ethiopia, 2014. 